\title{
Inhibition of eukaryotic translation elongation by the antitumor natural product Mycalamide B
}

\author{
YONGJUN DANG ${ }^{1,5}$ TILMAN SCHNEIDER-POETSCH, ${ }^{1,5,6}$ DANIEL E. EYLER, ${ }^{2}$ JOHN C. JEWETT, ${ }^{3}$ \\ SHRIDHAR BHAT, ${ }^{1}$ VIRESH H. RAWAL, ${ }^{3}$ RACHEL GREEN, ${ }^{2}$ and JUN O. LIU ${ }^{1,4,7}$ \\ ${ }^{1}$ Department of Pharmacology and Molecular Sciences, The Johns Hopkins University School of Medicine, Baltimore, Maryland 21205, USA \\ ${ }^{2}$ Department of Molecular Biology and Genetics, The Johns Hopkins University School of Medicine, Baltimore, Maryland 21205, USA \\ ${ }^{3}$ Department of Chemistry, The University of Chicago, Chicago, Illinois 60637, USA \\ ${ }^{4}$ Department of Oncology, The Johns Hopkins University School of Medicine, Baltimore, Maryland 21205, USA
}

\begin{abstract}
Mycalamide B (МусB) is a marine sponge-derived natural product with potent antitumor activity. Although it has been shown to inhibit protein synthesis, the molecular mechanism of action by MycB remains incompletely understood. We verified the inhibition of translation elongation by in vitro HCV IRES dual luciferase assays, ribosome assembly, and in vivo $\left[{ }^{35} \mathrm{~S}\right] \mathrm{methinione}$ labeling experiments. Similar to cycloheximide (CHX), MycB inhibits translation elongation through blockade of eEF2-mediated translocation without affecting the eEF1A-mediated loading of tRNA onto the ribosome, AUG recognition, or dipeptide synthesis. Using chemical footprinting, we identified the MycB binding site proximal to the C3993 285 rRNA residue on the large ribosomal subunit. However, there are also subtle, but significant differences in the detailed mechanisms of action of MycB and CHX. First, MycB arrests the ribosome on the mRNA one codon ahead of CHX. Second, MycB specifically blocked tRNA binding to the E-site of the large ribosomal subunit. Moreover, they display different polysome profiles in vivo. Together, these observations shed new light on the mechanism of inhibition of translation elongation by MycB.
\end{abstract}

Keywords: Mycalamide B; eukaryotic ribosome; translation elongation; tRNA

\section{INTRODUCTION}

Small molecules have played a big role in the elucidation of the structure and function of the ribosome in prokaryotes (Yonath 2005). More recently, high-throughput screening in conjunction with efforts to elucidate the mechanisms of action of antiproliferative natural products have led to the identification of several interesting inhibitors of eukaryotic translation (Novac et al. 2004; Low et al. 2005; Moore 2010; Schneider-Poetsch et al. 2010; Cencic et al. 2011). As translation plays an essential role in cell proliferation and survival, and fast-proliferating cancer cells are particularly dependent on protein synthesis, inhibitors of translation have potential in becoming useful leads in anticancer drug development.

\footnotetext{
${ }^{5}$ These two authors contributed equally to this work.

${ }^{6}$ Present address: Chemical Genetics Laboratory/Chemical Genomics Research Group, RIKEN Advanced Science Institute, Wako, Saitama 3510198, Japan.

${ }^{7}$ Corresponding author.

E-mail joliu@jhu.edu.

Article published online ahead of print. Article and publication date are at http://www.rnajournal.org/cgi/doi/10.1261/rna.2624511.
}

A number of inhibitors of prokaryotic translation have been used as antibiotics in the clinic over the past few decades (Poehlsgaard and Douthwaite 2005; Yonath 2005). More recently, several inhibitors of eukaryotic protein synthesis have entered the cancer drug development pipeline with a few advancing to Phase I and Phase II clinical trials, establishing translation as a promising target for chemotherapy (Pelletier and Peltz 2007). However, most of the translation inhibitors did not succeed in clinical trials, often due to dose-limiting toxicity. It has been proposed that translation inhibitors may be more effective and less toxic when administered in conjunction with other therapeutic agents (Pelletier and Peltz 2007). Aside from their clinical potential, the discovery of specific inhibitors of eukaryotic translation has enhanced our understanding of the similarities and differences between the translational apparatus of eukaryotes and bacteria. The discovery and characterization of new inhibitors of translation will likely improve our knowledge and offer leads to develop therapeutic agents.

Mycalamides $\mathrm{A}$ and $\mathrm{B}$ (MycA and $\mathrm{MycB}$ ) belong to a family of structurally related natural products of distinct origins including onnamide, pederin, and theopederins (Fig. 1). 

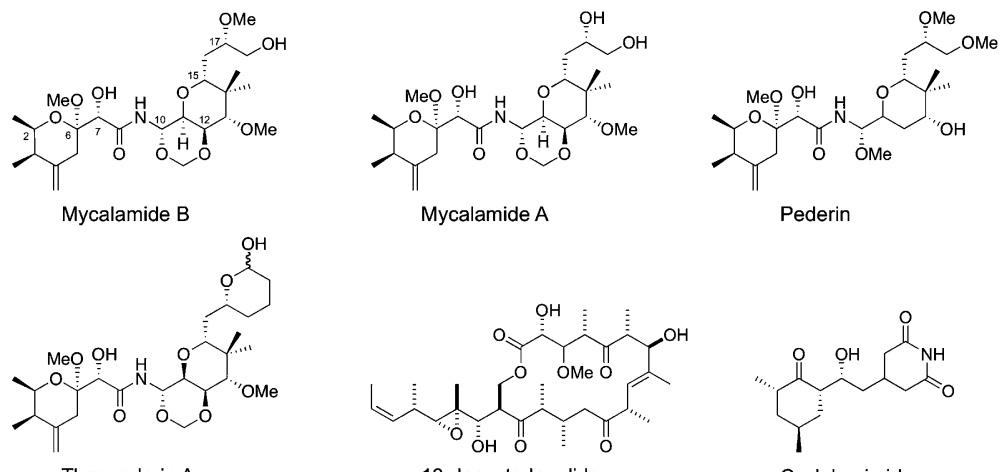

Mycalamide A

Pederin

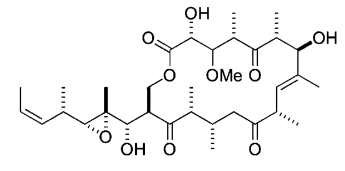

13-deoxytedanolide

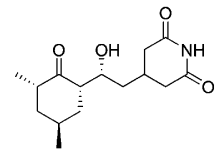

Cycloheximide
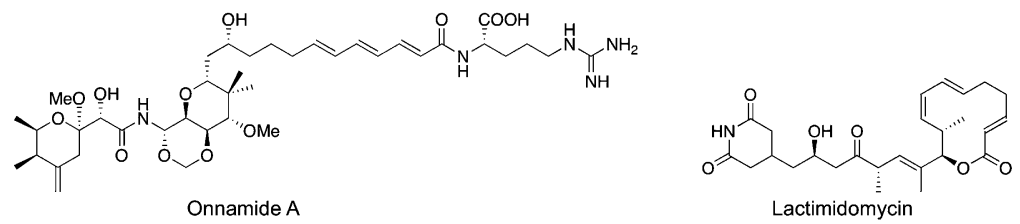

FIGURE 1. The structures of $\mathrm{MycB}$, its congeners, and other translation inhibitors.

tail of deacylated tRNA. Upon binding to the E-site, $\mathrm{MycB}$ prevents movement of the tRNA from the P-site to the E-site. Furthermore, $\mathrm{MycB}$ inhibits stress granule (SG) formation in vivo, as do other translation elongation inhibitors.

\section{RESULTS}

\section{Inhibition of translation underlies the antiproliferative effect of $\mathrm{MycB}$}

Although MycB has been reported to inhibit translation, it remains unclear whether this inhibition is responsible for its antiproliferative effect in cancer cells. To address this question, we determined the effect of $\mathrm{MycB}$ on both protein and RNA synthesis. We used a synthetic sample of $\mathrm{MycB}$ that has been previously fully characterized and struc-

Mycalamides were originally isolated from the marine sponge of the Mycale genus off the coast of New Zealand (Burres and Clement 1989). MycB possesses potent antitumor and immunosuppressive activities, inhibiting the growth of several tumor cell lines with $\mathrm{IC}_{50}$ values in the low nanomolar range and blocking T-cell activation in vitro (Burres and Clement 1989; Galvin et al. 1993). It can also reverse the morphological changes associated with Rastransformed NRK-cells to a normal state (Ogawara et al. 1991). Its congener MycA has a similar effect and has been shown to inhibit tumor growth in several murine allograft and human solid-tumor xenograft models (Burres and Clement 1989). Mycalamides and structurally related natural products have previously been reported to inhibit protein synthesis. For example, Pederin has been reported to inhibit translation at the translocation step (Brega et al. 1968; Barbacid et al. 1975). Recently, the structure of MycA bound to an archaeal (Haloarcula marismortui) ribosome was solved and it revealed that MycA binds to the E-site of the large ribosomal subunit (Gurel et al. 2009). Despite the structural information, however, how binding of MycA or $\mathrm{MycB}$ to the E-site of the large ribosomal subunit affects the function of the ribosome remains largely unknown. Furthermore, the structural study was based on an archaeal ribosome, which differs significantly from its eukaryotic counterpart.

To elucidate the mechanism of translation inhibition by $\mathrm{MycB}$ in eukaryotes, a biochemical approach was taken to dissect the translation step interfered by $\mathrm{MycB}$. The results confirmed that $\mathrm{MycB}$ primarily targets the translation elongation step in vivo and in vitro. Chemical footprinting of the large ribosomal subunit rRNA revealed that it binds to the same position in the E-site as the CCA turally verified (Jewett and Rawal 2010). We found the $\mathrm{IC}_{50}$ of the synthetic MycB against HeLa cell proliferation to be $\sim 1 \mathrm{nM}$, corroborating the earlier reports (Fig. 2A; Burres and Clement 1989). Cells were metabolically labeled with $\left[{ }^{35} \mathrm{~S}\right]$ methionine and cysteine or $\left[{ }^{3} \mathrm{H}\right]$ uridine for $2 \mathrm{~h}$ in the absence or presence of varying concentrations of $\mathrm{MycB}$. $\mathrm{MycB}$ was compared with the established translation and transcription inhibitors cycloheximide (CHX) and actinomycin D (Act D), respectively (Fig. 2B-D). MycB blocked protein synthesis in vivo at $\sim 12 \mathrm{nM}$ with little effect on transcription. Even at $1 \mu \mathrm{M}, \mathrm{MycB}$ suppressed RNA synthesis by $<50 \%$. We note that there is a significant difference in the observed $\mathrm{IC}_{50}$ values between cell proliferation and translation assays (Fig. 2E), which may be attributed to the different incubation times and intrinsic sensitivity of the different readouts.

\section{MyсB inhibits translation elongation}

While MycB's effect on translation in general has been observed previously (Burres and Clement 1989), whether it interferes with the initiation or elongation phase of protein synthesis has not been determined. To distinguish between those possibilities, we took advantage of internal ribosome entry sequences (IRES) from several viruses that can direct translation of target genes by bypassing the requirement for several canonical initiation factors. While the IRES of the hepatitis $\mathrm{C}$ virus (HCV) enables translation initiation without a functional eIF4F complex that contains the cap-binding proteins eIF4E and initiation factors eIF4A and eIF4G (Pestova et al. 1998), the IRES of the cricket paralysis virus (CrPV) circumvents the entire initiation apparatus (Jan and Sarnow 2002). 
A

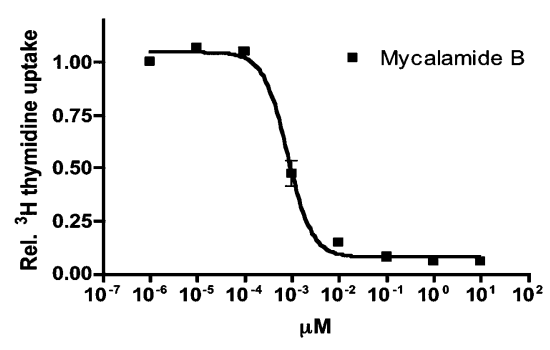

C

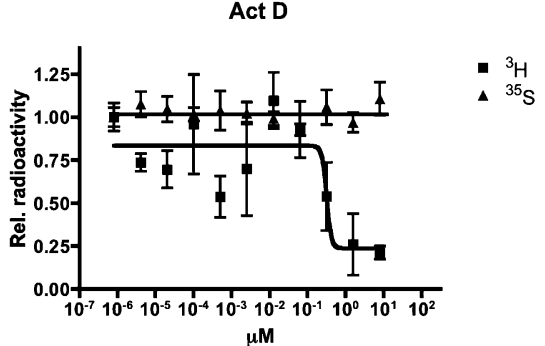

B

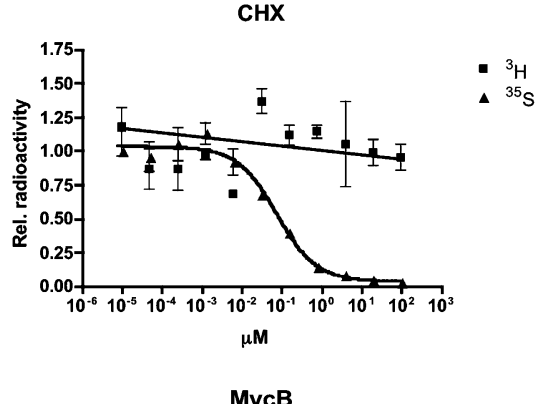

D

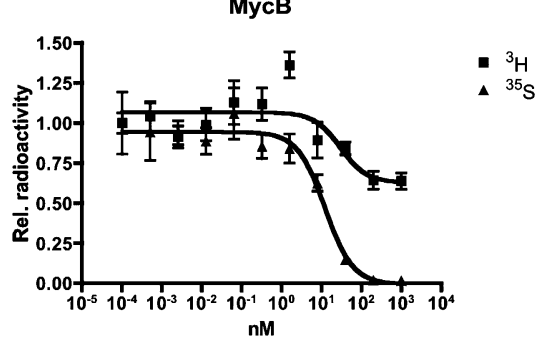

$E$

\begin{tabular}{lcc}
\hline Compound & $\mathrm{IC}_{50}$ of Translation & $\mathrm{IC}_{50}$ of Transcription \\
inhibition & inhibition \\
\hline Act D $(\mu \mathrm{M})$ & $\mathrm{ND}$ & 0.3 \\
Myc B $(\mathrm{nM})$ & 12.2 & $>1000$ \\
$\mathrm{CHX}(\mu \mathrm{M})$ & 0.07 & $\mathrm{ND}$ \\
\hline
\end{tabular}

FIGURE 2. MycB selectively inhibits translation. $(A) \mathrm{MycB}$ inhibits HeLa cell proliferation at an $\mathrm{IC}_{50}$ of $\sim 1 \mathrm{nM}$. $(B-D)$ HeLa cells were treated with different concentration of CHX $(B)$, Act $\mathrm{D}(C)$, and $\mathrm{MycB}(D)$, and labeled with $\left[{ }^{3} \mathrm{H}\right]$ uridine and $\left[{ }^{35} \mathrm{~S}\right]$ methionine and cystine for $2 \mathrm{~h}$. Cells were harvested and transferred onto glass fiber filters. Remaining radioactivity was counted and plotted. $(E) \mathrm{The}^{\mathrm{I}} \mathrm{IC}_{50}$ values of translation and transcription inhibition of $\mathrm{CHX}$, ActD and $\mathrm{MycB}$.

Transcribed HCV IRES and CrPV IRES dual luciferase reporters were used to perform in vitro translation assays with rabbit reticulocyte lysates. $\mathrm{MycB}$ dose-dependently inhibited cap-dependent translation and IRES-dependent translation of the mRNAs from both dual luciferase reporters (Fig. 3A,B). These results suggest that $\mathrm{MycB}$ inhibits translation at the elongation phase. Next, we carried out an in vitro translation sucrose gradient profiling in RRL to assess the distribution of ribosomal populations using the radioactivity of $\left[{ }^{32} \mathrm{P}\right] \mathrm{UTP}$ incorporated into rabbit $\beta$-globin mRNA as readout. As shown in Figure $3 \mathrm{C}$, $\mathrm{MycB}$ clearly blocked the ribosome after completing $80 \mathrm{~S}$ complex formation and had a similar effect on mRNA distribution as CHX. But, it differed from the mRNA distribution pattern obtained with the nonhydrolyzable GTP analog, GMPPNP, which prevents the GTP-dependent coupling of $60 \mathrm{~S}$ and $40 \mathrm{~S}$ subunits, consequently resulting in an increased $48 \mathrm{~S}$ population. The $80 \mathrm{~S}$ peak fractions were immediately used for toeprinting with a primer hybridized 60 nt downstream from the AUG start codon of rabbit $\beta$-globin mRNA. MycB caused the $80 \mathrm{~S}$ ribosome to stall at the start codon $($ or +17$)$ position of $\beta$-globin mRNA, which is similar to the effect of lactimidomycin (LTM), another translation elongation inhibitor recently characterized by our group (Fig. 3D; Schneider-Poetsch et al. 2010). For CHX, as reported, the $80 \mathrm{~S}$ arrests after one round of translocation at position +20 of the mRNA template (Supplemental Fig. 1). Together, these results indicated that MycB inhibits translation at the elongation phase similar to LTM and does not allow the ribosome to progress through a full elongation cycle.

\section{MycB inhibits eEF2-mediated ribosome translocation}

Translation elongation can be divided into three steps, beginning with the $G$ protein eEF1A delivering aminoacyltRNA to the empty A-site, followed by peptidyl transfer and the eEF2-mediated peptidyl-tRNA translocation from A-site to P-site, with concomitant transfer of deacylated tRNA from $\mathrm{P}$ to E-site. To determine which step was affected by $\mathrm{MycB}$, polyuridine-directed polyphenylalanyl synthesis was used (Fig. 4A). Using purified ribosomes, eEF1A, eEF2, GTP, and $\left[{ }^{15} \mathrm{C}\right]$ phenylalanine-charged tRNA, CHX, LTM, and $\mathrm{MycB}$ dramatically inhibited the synthesis of polyphenylalanine, though the percentages of inhibition were different. Furthermore, when the activity of eEF1 was measured in the presence of the above-mentioned inhibitors, none showed any inhibition (Fig. 4B), suggesting that $\mathrm{MycB}$ functions downstream from aminoacyl-tRNA binding to the A-site. Since eEF2 mediates peptidyl-tRNA translocation, we checked for possible inhibition of translocation by $\mathrm{MycB}$, CHX, and LTM by evaluating the puromycin reactivity 
A

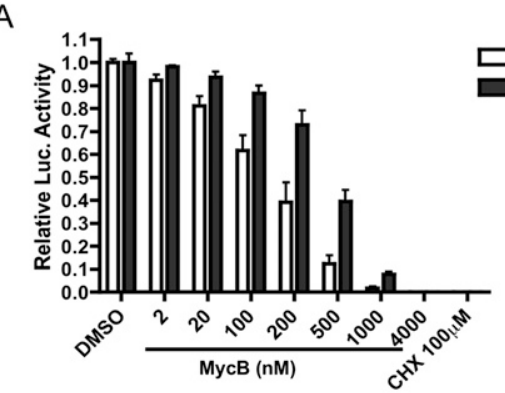

C

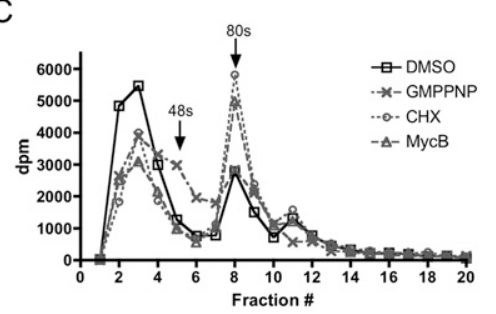

$\mathrm{B}$

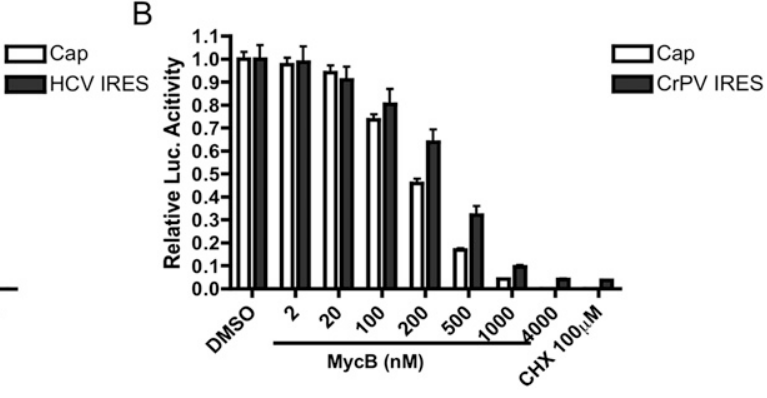

D

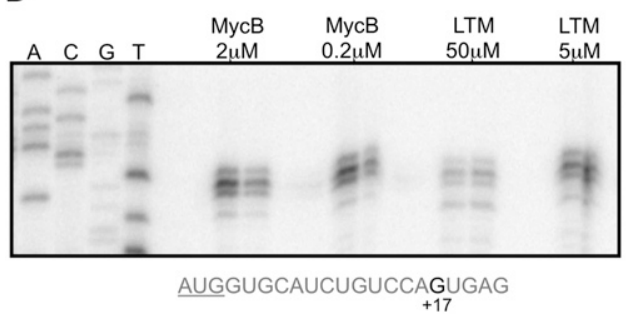

FIGURE 3. MycB inhibits translation elongation. $\mathrm{HCV}(A)$ and $\mathrm{CrPV}(B)$ IRES dual reporters were used in in vitro RRL translation assays in the presence of different concentrations of MycB and $100 \mu \mathrm{M}$ CHX. (C) ${ }^{32} \mathrm{P}$-labeled $\beta$-globin mRNA was incubated with RRL in the presence of GMPPNP, CHX, and MycB, and subjected to ultracentrifugation. The radioactivity of the aliquots was counted and the data were processed with GraphPad software. $(D)$ In a separate set of experiments 80 S fractions of lysates treated with the indicated compounds were collected and utilized in toeprinting assays by primer extension. The sequencing reactions were performed with full-length $\beta$-globin and separated on the far left four lanes.

of A-site tRNA. MycB blocked the movement of tRNA and prevented the formation of phenylalanyl-puromycin (Fig. 4C).

Up to this point, we had not ruled out an effect of $\mathrm{MycB}$ on peptide bond formation. We thus subjected $\mathrm{MycB}$ to a dipeptide and tripeptide formation assay using a short mRNA template coding for Met-Phe-Phe, which allows for a dynamic parsing of translation elongation. The products of the reaction were separated on an electrophoretic cellulose thin-layer chromatography plate. MycB inhibited tripeptide formation without affecting the formation of dipeptides (Fig. 4D,E). These results ruled out the possibility that $\mathrm{MycB}$ inhibited peptidyl transfer, corroborating our earlier observation that MycB blocked eEF2-mediated translocation.

\section{MycB gives rise to a footprint at the E-site of the larger ribosomal subunit}

Chemical footprinting has been widely used to map the site of binding of small molecule inhibitors to the ribosome. Previously, we have utilized this method to determine specific chemical footprints of both LTM and CHX on the large eukaryotic ribosomal subunit (Schneider-Poetsch et al. 2010). In the case of $\mathrm{MycB}$, the availability of an $\mathrm{X}$-ray crystal structure of its complex with the ribosome already provided a detailed view of how it interacts with the ribosome, albeit with the ribosome of an archaeal organism, in the E-site. This also offered a unique opportunity to determine how well results of chemical footprinting correlate with those from an X-ray structure. Thus, ribosomes were incubated with each of the inhibitors, followed by treatment with dimethyl sulfate (DMS). Footprints were obtained with extracted ribosome RNA by primer extension using avian myoblastoma (AMV) reverse transcriptase. Thus, treatment of ribosomes with DMS caused methylation of C3993 on the $28 \mathrm{~S}$ rRNA of the large ribosomal subunit among other bases in comparison with untreated control, giving rise to the corresponding footprint (Fig. 5A). Pretreatment of ribosomes with either MycB or LTM protected C3993 from DMS methylation, eliminating the C3993 footprint. It is worth noting that the C3993 footprint protection was also seen with CHX (Supplemental Fig. 2) but not emetine, another translation elongation inhibitor that does not bind the $\mathrm{E}$ site of the ribosome (Fig. 5A). We also titrated $\mathrm{MycB}$ in the footprinting assays to estimate its dissociation constant $\left(\mathrm{K}_{\mathrm{d}}\right)$ in comparison with that of CHX. Ribosomes were used at $50 \mathrm{nM}$. The $\mathrm{K}_{\mathrm{d}}$ is $\sim 260 \mathrm{nM}$ for $\mathrm{MycB}$ and $17 \mu \mathrm{M}$ for CHX (Fig. 5C; Supplemental Fig. 2), which is in agreement with the value reported previously (Schneider-Poetsch et al. 2010).

The binding of $\mathrm{MycB}$ to the E-site suggested that $\mathrm{MycB}$ should compete for binding with deacylated tRNA. To test this prediction, $\mathrm{MycB}$ was first incubated with purified $80 \mathrm{~S}$ ribosomes before ${ }^{32} \mathrm{P}$-labeled deacylated tRNA was added. The amount of ribosome-bound tRNA was determined by scintillation counting. MycB inhibited deacylated tRNA 
A

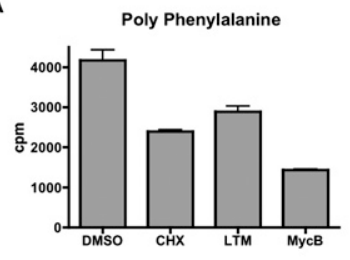

B

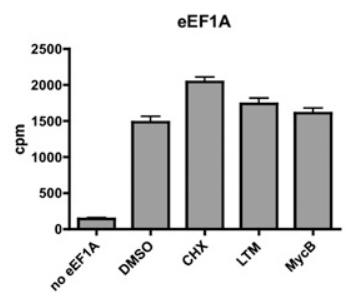

C

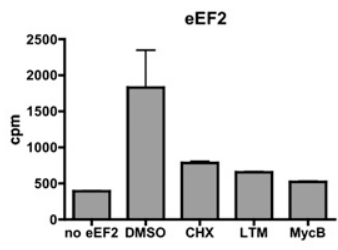

D

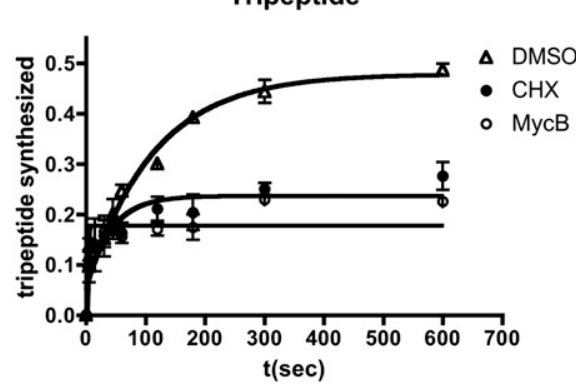

E

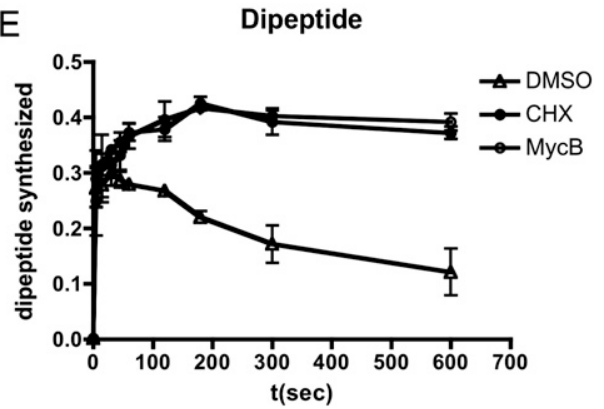

FIGURE 4. MycB inhibits translocation. (A) Polyuridine and ${ }^{14} \mathrm{C}$-labeled phenylalanine-charged tRNA ${ }^{\text {Phe }}$ were used in in vitro reassembled translation assays in the presence of $200 \mu \mathrm{M}$ CHX, $100 \mu \mathrm{M}$ LTM, and $20 \mu \mathrm{M}$ MycB. Synthesized polyphenylalanine was precipitated onto nitrocellulose filters and the radioactivity was counted. $(B)$ eEF1A-mediated tRNA binding was measured as described above, except that a higher amount of eEF1A was applied and GTP was replaced with GMPPNP. ${ }^{14} \mathrm{C}$-labeled Phenylalanyl-charged tRNA ${ }^{\text {Phe }}$ remaining on the ribosomes was detected after binding to a nitrocellulose membrane. $(C)$ eEF2-mediated translocation assays were performed in the presence of the three compounds. After the reaction, the final $\left[{ }^{14} \mathrm{C}\right]$ Phe-puromycin product was extracted with ethyl acetate and counted. $(D, E)$ Reassembled translation elongation was performed in the presence of DMSO, $2.6 \mu \mathrm{M} \mathrm{MycB}$, and $174 \mu \mathrm{M} \mathrm{CHX}$. The template was switched to a designated RNA encoding Met-Phe-Phe. $\left.{ }^{35} \mathrm{~S}\right]$ methionine-charged tRNA ${ }^{\mathrm{Met}}$ was used to label the synthesized peptide. The final tripeptide $(D)$ and dipeptide (E) products were separated by electrophoretic TLC, and were detected on a PhosphorImager plate and quantified using ImageQuant 5.2 software. The final values of dipeptide and tripeptide signals were normalized to the total amount of signal in the lane.

binding to the ribosome in a dose-dependent manner, albeit with significant background signal (data not shown). We suspected that deacylated tRNA bound nonspecifically to both $\mathrm{A}$ and $\mathrm{P}$ sites. To limit this nonspecific binding, we filled the A and P sites with Phe-charged tRNA (tRNA ${ }^{\text {phe }}$ ) and acetylated Phe-tRNA ${ }^{\text {phe }}$, each of which was purified by HPLC. For the same binding assay (Fig. 5D), the cold tRNA almost completely blocked binding of ${ }^{32} \mathrm{P}$-labeled deacylated tRNA, demonstrating that under these conditions all deacylated tRNA bound exclusively to the E-site. MycB did dose dependently prevent the deacylated tRNA from binding to the E site, as did LTM. As reported previously, CHX did not significantly compete with tRNA binding, even at $1 \mathrm{mM}$ concentration (Schneider-Poetsch et al. 2010).

\section{MycB inhibits stress granule formation through the blockade of translation elongation}

The buildup of $80 \mathrm{~S}$ ribosomes in vitro in the presence of $\mathrm{MycB}$ suggested that $\mathrm{MycB}$ would also change the distribution of ribosomal populations in vivo. We thus analyzed the polysome profile of HEK293T cells in the presence of $\mathrm{MycB}, \mathrm{CHX}$, and hippuristanol (Bordeleau et al. 2006), a translation initiation inhibitor. As shown in Figure 6A,
MycB treatment increased the amount of 80 S ribosomes, and oligoribosome, and decreased polysome levels in comparison to DMSO control. As expected, hippuristanol abolished polysomes and dramatically increased an apparent $80 \mathrm{~S}$ peak, due to its effect on translation initiation. However, in the case of translation initiation inhibitors such as hippuristanol or pateamine $\mathrm{A}$, this apparent $80 \mathrm{~S}$ fraction results from a cellular stress response (Low et al. 2005; Dang et al. 2006; Mazroui et al. 2006) and does not reflect an actual buildup of fully assembled ribosomes, as both compounds arrest translation long before ribosomal subunit joining occurs. Moreover, in the presence of $\mathrm{MycB}$, the increase of $80 \mathrm{~S}$ and oligoribosomes and the decrease of polysomes are dynamic and time dependent. After a 30min treatment, the polysome fractions appear to be completely wiped out by $\mathrm{MycB}$, but seem slightly increased under CHX treatment (Supplemental Fig. 3). The observed profile for $\mathrm{MycB}$ is in agreement with our expectations and underlines the mechanistic difference between $\mathrm{MycB}$ and $\mathrm{CHX}$. As previously reported, $\mathrm{CHX}$ stabilizes polysomes, as it can bind to the $\mathrm{E}$ site in the presence of a deacylated tRNA (Schneider-Poetsch et al. 2010), thereby also halting ribsomes that have traveled further downstream from the start codon. $\mathrm{MycB}$, which competes with the deacylated tRNA for binding, consequently inhibits protein synthesis 

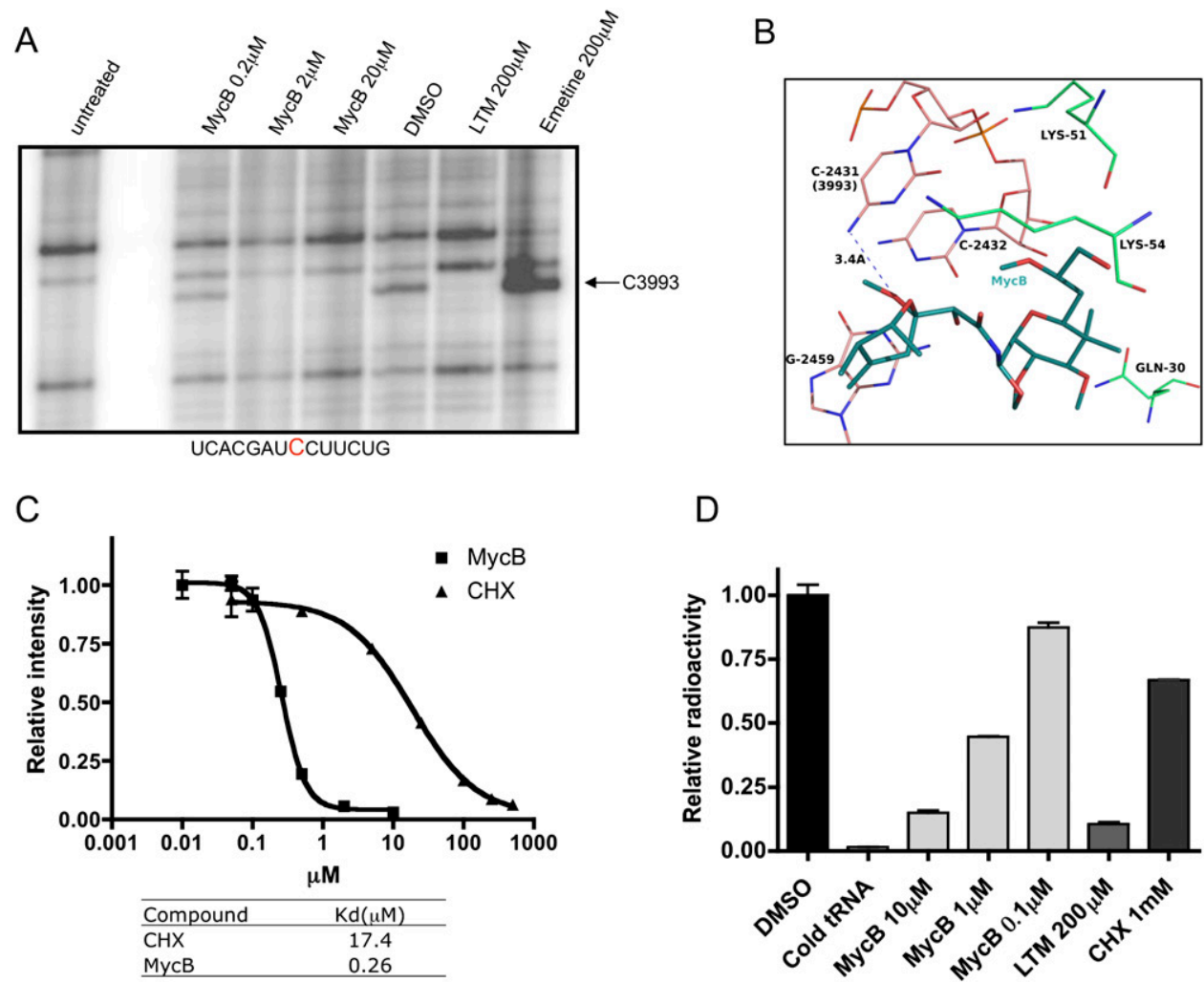

FIGURE 5. MycB is bound to $\mathrm{E}$ site of the larger ribosomal subunit. (A) Ribosomes were incubated with different compounds as indicated and then methylated with DMS. Extracted rRNAs were subjected to reverse transcription. rRNA not treated with DMS was labeled as "untreated" and served as a negative control. The ${ }^{32} \mathrm{P}$-labeled DNA was resolved on a denaturing polyacrylamide gel and was detected by PhosphorImager. $(B)$ Interaction of $\mathrm{MycB}$ with the $H$. marismortui ribosome (PDB ID: 3I55): A methyl group has been added onto the O-17 of MycA (original structure) to turn the structure into $\mathrm{MycB}$. The numberings correspond to $\mathrm{H}$. marismortui ribosome. Note the potential $\mathrm{H}$-bonding interaction between the 6-OMe group of $\mathrm{MycB}$ and N4-C2431. This is the conserved cytidine corresponding to C3993 in the eukaryotic ribosome for which we have shown chemical footprinting evidence. $(C)$ To measure the dissociation constants of MycB and CHX, ribosomes were incubated with serially diluted compounds and treated with DMS. Extracted rRNAs were subjected to reverse transcription. The ${ }^{32} \mathrm{P}-$ labeled DNA was resolved on a denaturing polyacrylamide gel and was detected by PhosphorImager. The intensity of the band was quantified and plotted using GraphPad software from two independent experiments. One gel is shown in Supplemental Figure 2. $(D)$ The E-site tRNA-binding assay was performed with purified ribosomes with the A and P site occupied by Phe-charged tRNA ${ }^{\text {Phe }}$ and the acetylated Phe-charged tRNA ${ }^{\text {Phe }}$, respectively. ${ }^{32} \mathrm{P}-$ labeled deacylated tRNA ${ }^{\text {Phe }}$ was added in the presence of the compounds as indicated. Ribosomes were bound to nitrocellulose membranes and the $\left[{ }^{32} \mathrm{P}\right]$ tRNA was measured by scintillation counting.

primarily during the first round of elongation before any tRNA reaches the E site, but appears not to halt actively elongating ribosomes, consequently permitting ribosome runoff. We note that while all experimental data are consistent with the aforementioned ribosome runoff model, we cannot rule out an alternative possibility that the polysome depletion in the presence of $\mathrm{MycB}$ resulted from the dissociation of the $80 \mathrm{~S}$ ribosome from both mRNA template and the peptidyl-tRNA upon exchange of MycB with deacylate tRNA in the E site. However, considering that $\mathrm{CHX}$ and $\mathrm{MycB}$ bind to the same position on the ribosome, it would be difficult to imagine why only one compound should lead to ribosome dissociation and not the other. Hence, the ribosomal runoff model appears to provide the more likely explanation.

The formation of stress granules (SGs) reflects the status of translation in vivo and is caused by disturbing the translation initiation process, either through induction of eIF2a phosphorylation or interference with the function of eIF4A. Since MycB inhibits translation at a relatively early stage and increases the $80 \mathrm{~S}$ peak, somewhat similar to hippuristanol or pateamine $\mathrm{A}$, we further determined whether $\mathrm{MycB}$ induced stress granule formation or whether it interfered with their production. The induction of SGs was performed in U2OS cells stably expressing GFP-tagged G3BP, a stress-granule marker (Kedersha et al. 2005). Upon MycB treatment, no SG was observed, in contrast to the treatment with arsenite, a known inducer of SGs (Fig. 6B). This result is similar to that obtained with CHX. In addition, pretreatment with $\mathrm{CHX}$ or $\mathrm{MycB}$ blocked the induction of SGs by arsenite, which is consistent with the previous reports that blocking translation elongation can prevent the SG formation (Kedersha et al. 2000). This result was further confirmed by the ablation of processing bodies 

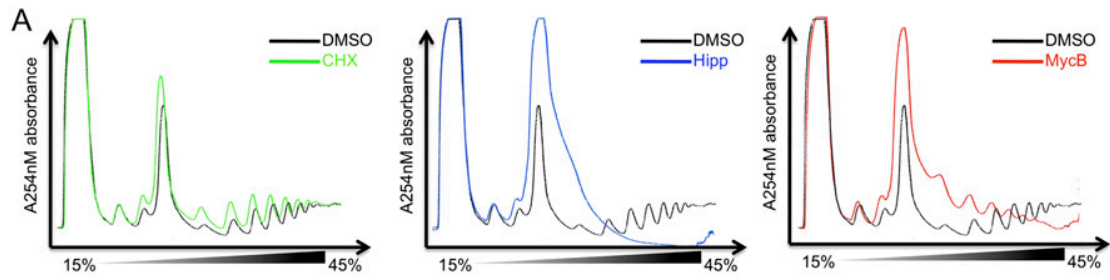

B
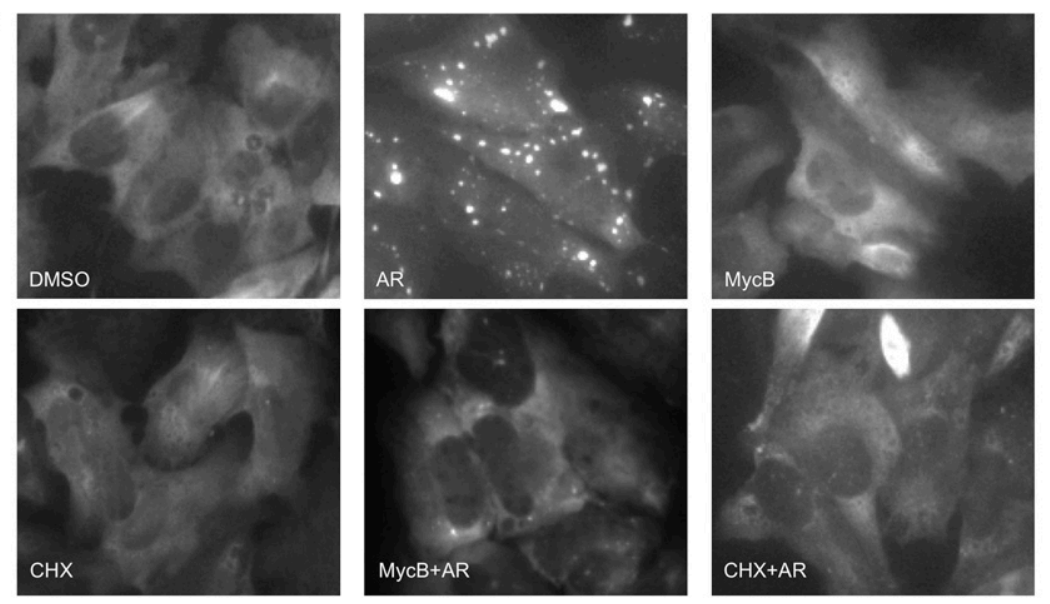

FIGURE 6. MycB affects polysome distribution and stress granule formation. (A) Polyribosome profiles determined from HEK293T cells after $1 \mathrm{~h}$ of treatment with $100 \mu \mathrm{g} / \mathrm{mL}$ CHX, $1 \mu \mathrm{M}$ hippuristanol, and $100 \mathrm{nM}$ MycB. (B) SGs induction performed in U2OS cells stably expressing GFP-G3BP in the presence of different compounds as indicated. The images were taken with an Axioskop microscope.

(PBs) by $\mathrm{MycB}$ treatment in a manner similar to $\mathrm{CHX}$ (Supplemental Fig. 4), as PB-formation can also be blocked by translation elongation inhibitors. The results further suggest that stress granule formation only occurs if translation initiation, but not elongation, is perturbed, and inhibition of elongation prevents SG formation.

\section{DISCUSSION}

The attainment of high-resolution structures of the ribosome has enabled rapid advances in the field of protein synthesis. In the case of antibacterial agents, it became possible to validate their mechanisms in unprecedented detail and to resolve minute details that evaded classic biochemical dissection (Yonath 2005; Moore 2010). Nevertheless, crystal structures only provide a single-frame snapshot of a dynamic process and biochemical verification is essential to fully understanding the mechanisms. Furthermore, crystallography has only recently advanced to resolving true eukaryotic ribosomes. Therefore, biochemical dissection adds credence to known structures obtained from prokaryotic organisms.

In this study we demonstrated that $\mathrm{MycB}$ inhibited eukaryotic translation elongation by occupying the large subunit's E site, thereby preventing translocation of deacylated tRNA from the $\mathrm{P}$ sie to the E site (Fig. 7). The result is consistent with the crystallographic data obtained on the closely related molecule $\mathrm{MycA}$, which was shown to bind to the E-site of the large archaeal ribosomal subunit. The present findings support the notion that the E-site portion of the ribosome shares significant similarity between Achaea and eukaryotes, but not bacteria (Gurel et al. 2009).

Three independent pieces of evidence support that $\mathrm{MycB}$ inhibits translation elongation. First, we were able to confirm inhibition of translation elongation, since $\mathrm{MycB}$ inhibited cap-dependent and initiation factor-independent IRES reporter translation. Furthermore, MycB inhibited in vitro polyphenylalanine synthesis in the absence of any initiation factor. Second, with ${ }^{32} \mathrm{P}$-labeled $\beta$-globin mRNA, MycB halted the translation progress after assembly of $80 \mathrm{~S}$ ribosome in RRL, in a manner similar to CHX. As CHX is significantly smaller than $\mathrm{MycB}$ or LTM, it can leave enough space for tRNA shuttling from the $\mathrm{P}$ site to the E site. Last, $\mathrm{MycB}$ has a toeprint similar to LTM (Schneider-Poetsch et al. 2010), another elongation inhibitor. The two GTPases, eEF1A and eEF2, as well as the ribosome, catalyze translation elongation. $\mathrm{MycB}$ dose-dependently inhibited eEF2-mediated translocation, but not eEF1A's function. MycB also did not interfere with peptide bond formation itself, as evidenced by the uninhibited formation of dipeptides in the presence of $\mathrm{MycB}$. Neither CHX nor $\mathrm{MycB}$ affected the formation of dipeptides, but clearly prevented the third amino acid from getting incorporated. At first the inhibition of tripeptide formation by $\mathrm{CHX}$ appears a bit surprising as CHX inhibits translation together with a deacylated tRNA. However, the reaction mixture contained a vast excess of free deacylated tRNA, which likely bound the ribosomal E site together with the small molecule, thereby allowing CHX to interrupt translation before the third peptide bond was formed.

Regarding the difference between the in vivo polysome profiles of $\mathrm{MycB}$ and $\mathrm{CHX}$, binding of the smaller $\mathrm{CHX}$ to the $\mathrm{E}$ site can occur simultaneously during the translation process and seems not limited to early elongation alone. However, $\mathrm{MycB}$ appears to mainly block translation when it occupies the empty E site before or during the first cycle of elongation, but allows ongoing translation elongation to run off. This explains the observed accumulation of $80 \mathrm{~S}$ ribosomes and oligoribosomes with a concomitant depletion of the polysome population. Since the polysome profile still shows some remaining polysomes in the presence of $\mathrm{MycB}$, it is possible that the small molecule occasionally binds between release of deacylated tRNA from the E site 


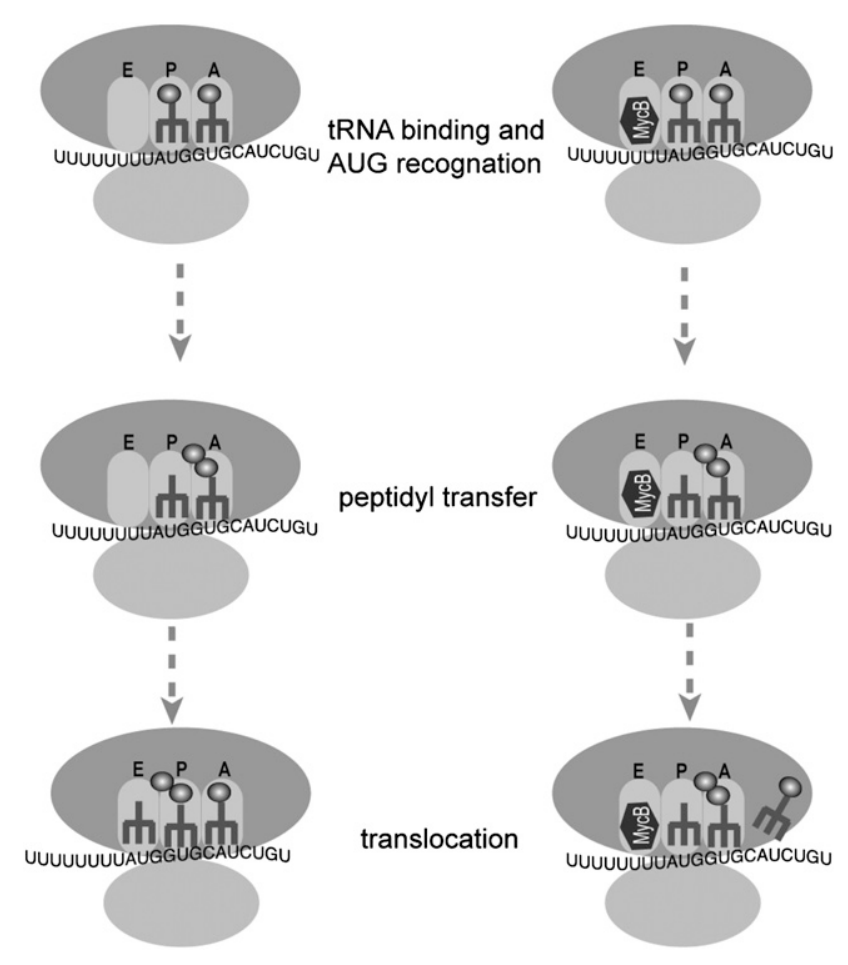

FIGURE 7. A model of the mechanism of action of MycB. (Left) Normal translation elongation; (right) MycB blocks deacylated tRNA progression elongation through binding to the E-site.

and the next round of translocation. The induction of SGs only occurs during translation initiation and can be suppressed by translation elongation inhibitors such as emetine and CHX (Kedersha et al. 2000; Dang et al. 2006; Anderson and Kedersha 2009). In the presence of $\mathrm{MycB}$, the induction of SGs by arsenite or pateamine A (data not shown) is attenuated in a manner similar to $\mathrm{CHX}$, indicating that the increase in $80 \mathrm{~S}$ ribosomes in vivo by $\mathrm{MycB}$ is unrelated to the induction of SGs, and that MycB is capable of suppressing the formation of SG at least as efficiently as CHX. Based on the $\mathrm{K}_{\mathrm{d}}$ of the two inhibitors, $\mathrm{MycB}$ exhibited a higher affinity for the ribosome with a dissociation constant of $260 \mathrm{nM}$, while CHX binds more loosely with a $\mathrm{K}_{\mathrm{d}}$ of $\sim 17$ $\mu \mathrm{M}$. We cannot rule out the possibility that this lower affinity also contributes to the different properties of the two inhibitors.

The MycB binding site identified by chemical footprinting agrees well with our mechanistic findings as well as with the reported archaeal crystal structure. The protected residue C3993 normally interacts with the $3^{\prime} \mathrm{OH}$ group of the deacylated tRNA (Schneider-Poetsch et al. 2010). As per the structural evidence, the 6-methoxy group of mycalamide lies within a hydrogen-bonding distance from $\mathrm{N}-4$ of C3993 (C2394 in Achaea) (Fig. 5B). Although MycB's 11-O and 7-OH may also form hydrogen bonds with other atoms of the 28S/23S rRNA, we did not observe any footprint other than C3993. The yeast ribosome crystal structure has recently been resolved at $4.15 \AA$ resolution
(Ben-Shem et al. 2010). A relevant snippet from the structural superimposition of MycA-bound archael ribosome and the yeast ribosome is shown in Supplemental Figure 5. Despite significant differences between the archaeal and yeast ribosomes, the E-site region where we have observed the footprint appears to superimpose remarkably well with the consensus nucleotide residues: G2459-G2793, C2431C2764, and C2432-C2765 from 23S of Archaea and 25S of yeast large ribosomal subunits, respectively. Cytidine-2431 (archaea), and C2764 (yeast) correspond to C3993 in the $28 \mathrm{~S}$ rRNA of the mammalian ribosome. On the other hand, ribosomal proteins L28 in bacteria, L44E in archaea, and L42 in the case of yeast occupy this region. In the MycAbound archaeal ribosome structure, Gln30, Lys54, and Lys51 (all from L44E) appear to make contacts with MycA. In contrast, in the overlay with yeast ribosome, Ala33, Pro56-Val57, and Thr54 (all from L42) are found to fill those spots. Given the divergence in the ribosomal proteins, the additional interactions of $\mathrm{MycB}$ with the higher eukaryotic ribosomal protein(s) may only be mapped when further biochemical or structural evidences become available.

The ability of $\mathrm{MycB}$ to compete with deacylated tRNA for E-site binding in a dose-dependent manner underscores the physiological relevance of the identified binding pocket. Binding of $\mathrm{MycB}$ to this position did come as a surprise considering that two other translation inhibitors, CHX and LTM, also protect C3993. While the two aforementioned molecules share significant structural similarity, $\mathrm{MycB}$ bears no resemblance to these two glutarimide-containing inhibitors. It is interesting to note that the binding of three different classes of inhibitors-CHX, LTM, and MycB, as well as 13-deoxytedanolide-converge on the eukaryotic E site, whereas none of the known antibacterial translation inhibitors work by a comparable mechanism. That the E site of eukaryotic ribosome is susceptible to inhibition by structurally distinct inhibitors with drastically different origins-bacteria for CHX and LTM and sea sponges for MycB and 13deoxytedanolide-suggest that this site has significantly different properties from its bacterial counterpart, which has been taken advantage of during the evolution of new bioactive natural products. It is intriguing as to why no antibiotics have been found to target the $\mathrm{E}$ site of the prokaryotic ribosome, given the abundance of antibiotics that target other essential processes in prokaryotes. It is possible that the very flexibility of the E site, as seen in yeast among the CHX- and LTM-resistant mutants, renders it easy to evolve resistance toward antibiotics targeting this site of the ribosome.

13-Deoxytedanolide is structurally related to the class of macrolide antibiotics that normally inhibit bacterial translation by blocking the nascent peptide tunnel, similar to erythromycin (Schroeder et al. 2007). It inhibits eukaryotic translation translocation through directly binding to ribosome large subunit. It can compete with pederin and its 
congeners, suggesting that it may target the same location on the 60S subunit. Interestingly, it cannot compete with $\mathrm{CHX}$, which shares the same binding site with $\mathrm{MycB}$ and LTM (Nishimura et al. 2005). Unlike its relatives, however, 13-deoxytedanolide does not inhibit bacterial protein synthesis. Thus far, no small molecule has been reported to target the E site of eubacterial ribosome (Yonath 2005; Moore 2010). This difference in specificity may be the result of distinct differences in protein composition at the $\mathrm{E}$ site of bacteria on one hand and eukaryotes and Achaea on the other. Binding of $\mathrm{MycB}$ appears to depend on ribosomal protein L44e (L36a in eukaryotes) (Gurel et al. 2009). In its place bacterial ribosomes contain the unrelated protein L28. Pederin, theopederins, mycalamides, onnamides, and icadamides are the major pederin polyketides that share, by-and-large, a common structural subunit called pederic acid that spans from O-1 to C-10, and their structures diverge only after C-10. A pharmacophore model that was advanced to account for the cellular effect of these polyketides concluded that the pederic acid subunit is the most critical and invariable moiety that is prone to loosing activity with slight changes of substitution or stereochemistry (Soldati et al. 1966; Burres and Clement 1989; Galvin et al. 1993; Richter et al. 1997; Narquizian and Kocienski 2000; West et al. 2000; Hood et al. 2001). It is highly likely that it is this very pederic acid portion of the translation inhibitors MycA, MycB, onnamide A, pederin, and theopederin $A$ that is responsible for conferring specificity for the ribosomal E-site (Fig. 1).

Considering the utility of antibiotics targeting protein biosynthesis and a pressing need for new clinical agents, development of a bacterial equivalent of the eukaryotic translation inhibitor LTM or MycB may prove extremely valuable. Understanding the mechanism of these inhibitors will facilitate their potential clinical application in cancer therapy.

\section{MATERIALS AND METHODS}

\section{Reagents and cell lines}

$\mathrm{MycB}$ and hippuristanol were synthesized as reported (Li et al. 2009; Jewett and Rawal 2010) and dissolved in DMSO. CHX, dimethyl sulfate (DMS), and actinomycin D were purchased from Sigma. Yeast tRNA ${ }^{\text {phe }}$ was purchased from Chemical Block. eEF1 and eEF2 were generously supplied by Dr. Merrick at Case Western Reserve University. All short RNAs were purchased from Invitrogen. HEK293T and HeLa cells were cultured in DMEM medium supplemented with $10 \%$ FBS and were maintained in a $5 \% \mathrm{CO}_{2}$ atmosphere. The vector $\mathrm{p} \beta-\mathrm{Hb}$ carrying $\beta$-globin cDNA was generously provided by Dr. Karen Browning at the University of Texas. The HCV IRES dual luciferase reporter vector was provided by Dr. Jerry Pelletier at McGill University and CrPV IRES dual luciferase reporter vector came from Dr. Peter Sarnow at Stanford University. U2OS cells expressing GFP-G3BP and RFP-Dcpla were provided by Drs. Paul Anderson and Nancy Kedersha at Harvard University.

\section{Metabolic labeling}

HeLa cells were used for cellular metabolic labeling experiments. For cell proliferation assays, cells were plated onto 96 well plates at 5000 cells per well, allowed to adhere overnight, and treated with different concentrations of $\mathrm{MycB}$ as indicated in Figure 2 for $18 \mathrm{~h}$. The cells were then labeled with $\left[{ }^{3} \mathrm{H}\right]$ thymidine $(1 \mu \mathrm{Ci}$ per well) (PerkinElmer) for another $6 \mathrm{~h}$. Cells were printed onto GF/C glass fiber filters using a Tomtec harvester and washed before the activity of the remainder of $\left[{ }^{3} \mathrm{H}\right]$ thymidine on the filters was counted.

For in vivo transcription and translation assays, 10,000 cells per well in 96-well plates were labeled by $\left[{ }^{3} \mathrm{H}\right]$ uridine $(1 \mu \mathrm{Ci}$ per well) (PerkinElmer) or the mixture of $\left.{ }^{35} \mathrm{~S}\right]$ methionine and cystine (PerkinElmer) $(0.5 \mu \mathrm{Ci}$ per well) for $2 \mathrm{~h}$ in the presence of different compounds at increasing concentrations as indicated in Figure 2. For in vivo transcription assays, cells were harvested and processed as stated above for the cell proliferation assay. For the in vivo translation measurements, after labeling, cells were washed with PBS and lysed with RIPA buffer. The total proteins were precipitated with 5\% trichloroacetic acid (TCA) and passed through a filter. After extensively washing with 5\% TCA and drying, the filters were scintillation counted.

\section{Dual luciferase reporter assay}

HCV and CrPV IRES dual luciferase reporter vectors were linearized with BamHI (NEB) and transcribed using SP6 or T7 polymerase (Promega) (Novac et al. 2004). Briefly, each reaction was performed using $10 \mu \mathrm{L}$ of the Flexi rabbit reticulocyte lysate (RRL, from Promega), $200 \mathrm{ng}$ of RNA, $0.2 \mu \mathrm{L}$ each of Met and Leu amino acid mixtures, $70 \mathrm{mM} \mathrm{KCl}, 2 \mathrm{mM}$ DTT, and $10 \mathrm{U}$ of RNaseout (Invitrogen) in $20 \mu \mathrm{L}$ with the indicated concentration of compounds. The mixtures were incubated at $30^{\circ} \mathrm{C}$ for $1 \mathrm{~h}$ and the reaction was quenched with $20 \mu \mathrm{L}$ of passive lysis buffer (Promega), and a $10-\mu \mathrm{L}$ aliquot was assayed for luciferase activity according to the instructions of the manufacturer (Dual-Luciferase reporter assay system; Promega).

\section{Polyphenylalanine synthesis, eEF1, and eEF2 assays}

Both methods were described in our previous report (SchneiderPoetsch et al. 2010). Briefly, yeast RNA $^{\text {phe }}$ was charged with $\left[{ }^{14} \mathrm{C}\right]$ phenylalanine and used for both assays, with a specific activity of $\sim 1300 \mathrm{cpm}$ per picomol. 80 s ribosomes were purifed from RRL. For polyphenylalanine synthesis, $8 \mu \mathrm{g}$ of polyuridine RNA, 0.4 OD260 of ribosomes, $2 \mu \mathrm{g}$ of eEF1A, $0.5 \mu \mathrm{g}$ of eEF2, 10 pmol of $\left[{ }^{14} \mathrm{C}\right] \mathrm{Phe} \mathrm{tRNA}^{\text {Phe }}$ in $30 \mathrm{mM}$ Tris- $\mathrm{HCl}(\mathrm{pH} 7.4), 100 \mathrm{mM}$ $\mathrm{KCl}, 10 \mathrm{mM} \mathrm{MgCl} 2,1 \mathrm{mM}$ DTT, $1 \mathrm{mM}$ GTP, $2.1 \mathrm{mM}$ phosphoenol pyruvate, and $0.3 \mathrm{U}$ pyruvate kinase were incubated for $5 \mathrm{~min}$ at room temperature with the compounds as indicated in Figure 4. Reactions were quenched with $1 \mathrm{~mL}$ of cold $10 \%$ TCA and boiled for $15 \mathrm{~min}$. The samples were filtered through nitrocellulose filters and washed thee times with 5\% TCA before scintillation counting. For the eEF1 assays, 89 pmol of ribosomes, $200 \mathrm{ng}$ of polyuridylic acid, $10 \mathrm{pmol}$ of $\left[{ }^{14} \mathrm{C}\right]$ Phe tRNA ${ }^{\text {Phe }}, 2.2 \mu \mathrm{g}$ of eEF1 and $150 \mu \mathrm{M}$ of GDPPNP were incubated in the buffer (20 mM Hepes-KOH at pH 7.4, $100 \mathrm{mM} \mathrm{KCl}, 10 \mathrm{mM} \mathrm{MgCl} 2$, and $1 \mathrm{mM} \mathrm{DTT}$ ) in the presence of the compounds as indicated in Figure 4, with eEF1A and tRNA being added last. The mixtures 
were reacted for $10 \mathrm{~min}$ at $37^{\circ} \mathrm{C}$ and diluted with a milliliter of the same buffer and immediately filtered through nitrocellulose and counted afterward. For eEF2 assay, the reaction was set up the same way as eEF1 assay, except GTP was used instead of GDPPNP. After incubation with the compounds as shown in Figure $4,4.5 \mu \mathrm{L}$ of 10x buffer, $0.5 \mu \mathrm{g}$ of eEF2, $10 \mu \mathrm{L}$ of $10 \mathrm{mg} / \mathrm{mL}$ puromycin, and $6 \mu \mathrm{L}$ of $15 \mathrm{mM}$ GTP were added and reacted for $10 \mathrm{~min}$ at $37^{\circ} \mathrm{C}$. The reaction was quenched with $1.4 \mathrm{~mL}$ of cold ethyl acetate and thoroughly vortexed. The organic phase was separated by centrifugation and $1-\mathrm{mL}$ aliquots were counted after mixing with scintillation cocktail.

\section{Chemical footprints}

The ribosomal RNA footprints were performed as described before (Merryman and Noller 1998; Schneider-Poetsch et al. 2010). Briefly, the purified $80 \mathrm{~S}$ ribosomes were incubated with the indicated compounds at increasing concentrations (CHX [500, $250,100,25,5,0.5$, and $0.05 \mu \mathrm{M}]$ and $\mathrm{MycB}[10,2,0.5,0.25,0.1$, 0.05 , and $0.01 \mu \mathrm{M}]$ ) and treated with $90 \mathrm{mM}$ DMS at $37^{\circ} \mathrm{C}$ for $5 \mathrm{~min}$. The rRNAs were isolated with the RNAqueous kit from Ambion. Then, isolated rRNAs were used for primer extension (primer sequence: $5^{\prime}$-CTGCGTTACCGTTTGAC). The final DNA products were extracted and resolved on a DNA sequencing gel. The gel was dried and exposed to a PhosphorImager.

\section{tRNA binding assay}

Deacylated tRNA ${ }^{\text {Phe }}$ was labeled with ${ }^{32} \mathrm{P}$ as described previously (Ledoux and Uhlenbeck 2008; Walker and Fredrick 2008). Briefly, A $50-\mu \mathrm{L}$ reaction containing $1 \mu \mathrm{M}$ tRNA ${ }^{\text {Phe }}, 50 \mu \mathrm{M}$ of sodium pyrophosphate, $0.2 \mu \mathrm{M}$ tRNA nucleotidyl transferase (CCA adding enzyme), $0.3 \mu \mathrm{M}\left[\alpha-{ }^{32} \mathrm{P}\right] \mathrm{ATP}$ in the buffer $\left(20 \mathrm{mM} \mathrm{MgCl}_{2}\right.$ and $50 \mathrm{mM}$ Tris- $\mathrm{HCl}$ at $\mathrm{pH} 7.5)$, were incubated at $37^{\circ} \mathrm{C}$ for $5 \mathrm{~min}$. CTP $(1 \mu \mathrm{M}$ final concentration) was added with $10 \mathrm{U} / \mathrm{mL}$ of yeast inorganic pyrophosphatase and incubated for two additional min. tRNA was extracted with phenol and chloroform and purifed through G50 columns (GE Healthcare).

To make acetylated Phe-charged tRNA ${ }^{\text {Phe }}$, after the charging reaction the reaction mixture was first desalted using a PD10 desalting column (GE Healthcare) and then purified by HPLC. Purified tRNA was diluted to $1.6 \mu \mathrm{M}$ in $250 \mu \mathrm{L}$ of cold $200 \mathrm{mM}$ $\mathrm{NaOAc}(\mathrm{pH} 5.2)$. Acetic anhydride $(4 \mu \mathrm{L})$ was added to each tube and incubated on ice for $1 \mathrm{~h}$, with the process being repeated one more time. The product was precipitated by ethanol and kept at $-80^{\circ} \mathrm{C}$ until use. A $50-\mu \mathrm{L}$ reaction contained $2 \mu \mathrm{g}$ of polyuridine RNA, 2 pmol ribosomes, 6 pmol each of Phe-tRNA ${ }^{\text {Phe }}$ and acylated Phe-tRNA ${ }^{\text {Phe }}$ in the presence of the test compounds or $4 \mu \mathrm{M}$ cold tRNA in $30 \mathrm{mM}$ Hepes- $\mathrm{KOH}$ ( $\mathrm{pH} 7.4$ ), $25 \mathrm{mM} \mathrm{MgCl}$, $100 \mathrm{mM}$ KOAc, $0.25 \mathrm{M}$ sucrose for $10 \mathrm{~min}$. Deacylated tRNA ${ }^{\text {Phe }}$ labeled with ${ }^{32} \mathrm{P}(6 \mathrm{pmol})$ was added and incubated at $37^{\circ} \mathrm{C}$ for 5 $\min$. The reaction was stopped by the addition of the same buffer $(1 \mathrm{~mL}, 1 \mathrm{x})$ before being filtered through a nitrocellulose membrane. The dried filter was assayed using a scintillation counter.

\section{Dipeptide and tripeptide sythesis assay}

The $80 \mathrm{~S}$ initiation complexes were assembled essentially as described previously (Acker et al. 2007; Saini et al. 2009) with slight modifications. A different reaction buffer $(20 \mathrm{mM}$ Tris- $\mathrm{Cl}$ at $\mathrm{pH}$
7.5, $100 \mathrm{mM}$ potassium acetate at $\mathrm{pH} 7.6,2.5 \mathrm{mM}$ magnesium acetate, $0.25 \mathrm{mM}$ spermidine, $2 \mathrm{mM}$ DTT) was used and tRNA ${ }^{\text {Met }}$ was labeled exclusively with $\left[{ }^{35} \mathrm{~S}\right]$ Met. In addition, the mRNA contained the ORF sequence AUGUUCUUCUAA. After assembly, initiation complexes were layered onto reaction buffer containing 1.1 $\mathrm{M}$ sucrose and centrifuged for $1 \mathrm{~h}$ at 424,000 $\mathrm{g}$ in a TLA-100.3 rotor. Complexes were resuspended in reaction buffer, flashfrozen, and stored at $-80^{\circ} \mathrm{C}$. For each elongation reaction, PhetRNA $^{\text {Phe }}$ ternary complex was prepared. Each batch of ternary complex contained the following reagents: 60 pmol eEF1A, 50 fmol Met-tRNA ${ }^{\text {Met }}, 25.6$ pmol Phe-tRNA $^{\text {Phe }}, 4$ pmol eEF2, 4 pmol eEF3, $1.3 \mathrm{mM}$ GTP, $0.4 \mathrm{mM}$ ATP, drug at 10 times the $\mathrm{K}_{\mathrm{d}}$ or $\mathrm{DMSO}$, and $1 \mathrm{x}$ reaction buffer, and was incubated at $26^{\circ} \mathrm{C}$ for 15 min. During the incubation, initiation complex was thawed and incubated with drug at ten times the $\mathrm{K}_{\mathrm{d}}$ or vehicle for $3 \mathrm{~min}$. At the end of this incubation, the ternary complex was mixed with the initiation complex and incubated at $26^{\circ} \mathrm{C}$. Aliquots were removed at the indicated times and quenched in $50 \mathrm{mM} \mathrm{KOH}$. Reaction products were separated by electrophoresis on cellulose TLC plates (pyridine-acetate buffer at $\mathrm{pH} 2.8 ; 1200 \mathrm{~V}, \sim 35 \mathrm{~min}$ ). The dipeptide signal is the fraction of all peptides that are MetPhe. In the case of tripeptide, it is the amount of tripeptide MetPhe-Phe. $\left[{ }^{35} \mathrm{~S}\right]$ Met-containing reaction products were detected by PhosphorImaging and quantified using ImageQuant 5.2 software (GE Healthcare Life Sciences). The values in Figure 4, D and E, for dipeptide and tripeptide, are normalized to the total amount of available reactive material.

\section{Cellular polysome fractionation}

HEK293T cells were treated with different compounds for $1 \mathrm{~h}$, then washed once with ice-cold PBS and lysed by pipetting in TMK100 buffer (20 mM Tris-Hcl at $\mathrm{pH} 7.4,5 \mathrm{mM} \mathrm{MgCl}_{2} 100$ $\mathrm{mM} \mathrm{KCl}, 2 \mathrm{mM}$ DTT, $1 \%$ Triton X-100), $100 \mathrm{U} / \mathrm{mL}$ RNasin (Promega) and protease inhibitors (Roche Diagnostics). After spinning at $10,000 \mathrm{~g}(10 \mathrm{~min})$ at $4^{\circ} \mathrm{C}$, the supernatants were loaded onto $10 \mathrm{~mL}, 10 \%-40 \%$ linear sucrose gradients containing $20 \mathrm{mM}$ HEPES (pH 7.4), $100 \mathrm{mM} \mathrm{KCl,} 5 \mathrm{mM} \mathrm{MgCl}_{2}$, and $2 \mathrm{mM}$ DTT. Ultracentrifugation at $40,000 \mathrm{rpm}$ for $2 \mathrm{~h}$ at $4^{\circ} \mathrm{C}$ was performed in a SW41Ti rotor (Beckman). Gradient profiles were monitored at $254 \mathrm{~nm}$ from top to bottom.

\section{Processing bodies and induction of stress granules}

U2OS cells stably expressing GFP-G3BP and RFP-Dcp1 $\alpha$ were treated with the indicated compounds for $1 \mathrm{~h}$ and then fixed with $4 \%$ polyformaldehyde. The cells were examined with an Axioskop microscope (Carl Zeiss, Inc.). Images were captured with a Sensys CCD camera (Photometrics Ltd.) using IP Lab software v3.1 (Scanalytics).

\section{SUPPLEMENTAL MATERIAL}

Supplemental material is available for this article.

\section{ACKNOWLEDGMENTS}

We are grateful to Drs. Paul Englund, Gerald Hart, and Daniel Lane for their generous provision of advice and access to special 
equipment. We thank Drs. Nancy Kedersha, Paul Anderson, Peter Sarnow, Jerry Pelletier, Karen Browning, and William Merrick for reagents and plasmids. We thank Shan $\mathrm{He}$ and Wei Shi for assistance with the performance of experiments and preparation of the manuscript. This work was supported by a discretionary fund of the Liu Lab and the Keck Foundation (J.O.L.).

Received January 10, 2011; accepted May 19, 2011.

\section{REFERENCES}

Acker MG, Kolitz SE, Mitchell SF, Nanda JS, Lorsch JR. 2007. Reconstitution of yeast translation initiation. Methods Enzymol 430: 111-145.

Anderson P, Kedersha N. 2009. Stress granules. Curr Biol 19: R397R398.

Barbacid M, Fresno M, Vazquez D. 1975. Inhibitors of polypeptide elongation on yeast polysomes. J Antibiot (Tokyo) 28: 453-462.

Ben-Shem A, Jenner L, Yusupova G, Yusupov M. 2010. Crystal structure of the eukaryotic ribosome. Science 330: 1203-1209.

Bordeleau ME, Mori A, Oberer M, Lindqvist L, Chard LS, Higa T, Belsham GJ, Wagner G, Tanaka J, Pelletier J. 2006. Functional characterization of IRESes by an inhibitor of the RNA helicase eIF4A. Nat Chem Biol 2: 213-220.

Brega A, Falaschi A, De Carli L, Pavan M. 1968. Studies on the mechanism of action of pederine. J Cell Biol 36: 485-496.

Burres NS, Clement JJ. 1989. Antitumor activity and mechanism of action of the novel marine natural products mycalamide-A and -B and onnamide. Cancer Res 49: 2935-2940.

Cencic R, Hall DR, Robert F, Du Y, Min J, Li L, Qui M, Lewis I, Kurtkaya S, Dingledine R, et al. 2011. Reversing chemoresistance by small molecule inhibition of the translation initiation complex eIF4F. Proc Natl Acad Sci 108: 1046-1051.

Dang Y, Kedersha N, Low WK, Romo D, Gorospe M, Kaufman R, Anderson P, Liu JO. 2006. Eukaryotic initiation factor $2 \alpha$-independent pathway of stress granule induction by the natural product pateamine A. J Biol Chem 281: 32870-32878.

Galvin F, Freeman GJ, Razi-Wolf Z, Benacerraf B, Nadler L, Reiser H. 1993. Effects of cyclosporin A, FK 506, and mycalamide A on the activation of murine CD4+ T cells by the murine B7 antigen. Eur J Immunol 23: 283-286.

Gurel G, Blaha G, Steitz TA, Moore PB. 2009. Structures of triacetyloleandomycin and mycalamide A bind to the large ribosomal subunit of Haloarcula marismortui. Antimicrob Agents Chemother 53: $5010-5014$.

Hood KA, West LM, Northcote PT, Berridge MV, Miller JH. 2001. Induction of apoptosis by the marine sponge (Mycale) metabolites, mycalamide A and pateamine. Apoptosis 6: 207-219.

Jan E, Sarnow P. 2002. Factorless ribosome assembly on the internal ribosome entry site of cricket paralysis virus. J Mol Biol 324: 889902.

Jewett JC, Rawal VH. 2010. Temporary restraints to overcome steric obstacles: an efficient strategy for the synthesis of mycalamide B. Angew Chem Int Ed Engl 49: 8682-8685.

Kedersha N, Cho MR, Li W, Yacono PW, Chen S, Gilks N, Golan DE, Anderson P. 2000. Dynamic shuttling of TIA-1 accompanies the recruitment of mRNA to mammalian stress granules. J Cell Biol 151: $1257-1268$.

Kedersha N, Stoecklin G, Ayodele M, Yacono P, Lykke-Andersen J, Fritzler MJ, Scheuner D, Kaufman RJ, Golan DE, Anderson P. 2005. Stress granules and processing bodies are dynamically linked sites of mRNP remodeling. J Cell Biol 169: 871-884.

Ledoux S, Uhlenbeck OC. 2008. [ $\left[3^{\prime}-{ }^{32} \mathrm{P}\right]$-labeling tRNA with nucleotidyltransferase for assaying aminoacylation and peptide bond formation. Methods 44: 74-80.
Li W, Dang Y, Liu JO, Yu B. 2009. Expeditious synthesis of hippuristanol and congeners with potent antiproliferative activities. Chemistry 15: 10356-10359.

Low WK, Dang Y, Schneider-Poetsch T, Shi Z, Choi NS, Merrick WC, Romo D, Liu JO. 2005. Inhibition of eukaryotic translation initiation by the marine natural product pateamine A. Mol Cell 20: 709-722.

Mazroui R, Sukarieh R, Bordeleau ME, Kaufman RJ, Northcote P, Tanaka J, Gallouzi I, Pelletier J. 2006. Inhibition of ribosome recruitment induces stress granule formation independently of eukaryotic initiation factor $2 \alpha$ phosphorylation. Mol Biol Cell 17: 4212-4219.

Merryman C, Noller HF. 1998. Foot-printing and modificationinterference analysis of binding sites on RNA. In RNA-protein interactions: a practical approach (ed. CWJ Smith), p. 237-253. Oxford University Press, Oxford, New York.

Moore P. 2010. Inhibitors of the large ribosomal subunit from Haloarcula marismortui. Isr J Chem 50: 36-44.

Narquizian R, Kocienski PJ. 2000. The pederin family of antitumor agents: structures, synthesis and biological activity. Ernst Schering Res Found Workshop 32: 25-56.

Nishimura S, Matsunaga S, Yoshida M, Hirota H, Yokoyama S, Fusetani N. 2005. 13-Deoxytedanolide, a marine sponge-derived antitumor macrolide, binds to the 605 large ribosomal subunit. Bioorg Med Chem 13: 449-454.

Novac O, Guenier AS, Pelletier J. 2004. Inhibitors of protein synthesis identified by a high throughput multiplexed translation screen. Nucleic Acids Res 32: 902-915.

Ogawara H, Higashi K, Uchino K, Perry NB. 1991. Change of rastransformed NRK-cells back to normal morphology by mycalamides $\mathrm{A}$ and $\mathrm{B}$, antitumor agents from a marine sponge. Chem Pharm Bull (Tokyo) 39: 2152-2154.

Pelletier J, Peltz SW. 2007. Therapeutic opportunities in translation. In Translational control in biology and medicine (ed. MB Mathews, N Sonenberg, JWB Hershey), pp. 855-895. Cold Spring Harbor Laboratory Press, Cold Spring Harbor, NY.

Pestova TV, Shatsky IN, Fletcher SP, Jackson RJ, Hellen CU. 1998. A prokaryotic-like mode of cytoplasmic eukaryotic ribosome binding to the initiation codon during internal translation initiation of hepatitis C and classical swine fever virus RNAs. Genes Dev 12: 67-83.

Poehlsgaard J, Douthwaite S. 2005. The bacterial ribosome as a target for antibiotics. Nat Rev Microbiol 3: 870-881.

Richter A, Kocienski P, Raubo P, Davies DE. 1997. The in vitro biological activities of synthetic 18-O-methyl mycalamide B, 10epi-18-O-methyl mycalamide B and pederin. Anticancer Drug Des 12: $217-227$.

Saini P, Eyler DE, Green R, Dever TE. 2009. Hypusine-containing protein eIF5A promotes translation elongation. Nature 459: 118121.

Schneider-Poetsch T, Ju J, Eyler DE, Dang Y, Bhat S, Merrick WC, Green R, Shen B, Liu JO. 2010. Inhibition of eukaryotic translation elongation by cycloheximide and lactimidomycin. Nat Chem Biol 6: 209-217.

Schroeder SJ, Blaha G, Tirado-Rives J, Steitz TA, Moore PB. 2007. The structures of antibiotics bound to the $\mathrm{E}$ site region of the $50 \mathrm{~S}$ ribosomal subunit of Haloarcula marismortui: 13-deoxytedanolide and girodazole. J Mol Biol 367: 1471-1479.

Soldati M, Fioretti A, Ghione M. 1966. Cytotoxicity of pederin and some of its derivatives on cultured mammalian cells. Experientia 22: $176-178$.

Walker SE, Fredrick K. 2008. Preparation and evaluation of acylated tRNAs. Methods 44: 81-86.

West LM, Northcote PT, Hood KA, Miller JH, Page MJ. 2000. Mycalamide D, a new cytotoxic amide from the New Zealand marine sponge Mycale species. J Nat Prod 63: 707-709.

Yonath A. 2005. Antibiotics targeting ribosomes: resistance, selectivity, synergism and cellular regulation. Annu Rev Biochem 74: 649679. 

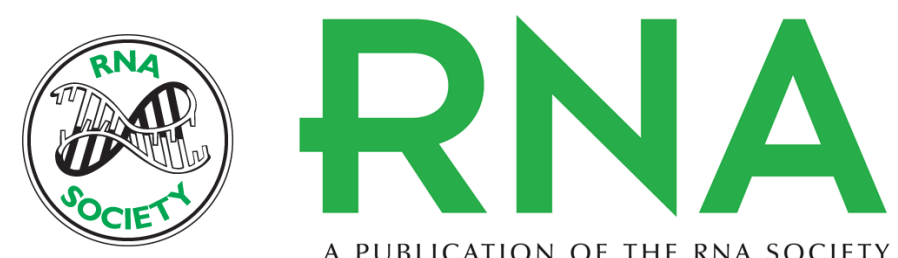

A PUBLICATION OF THE RNA SOCIETY

\section{Inhibition of eukaryotic translation elongation by the antitumor natural product Mycalamide B}

Yongjun Dang, Tilman Schneider-Poetsch, Daniel E. Eyler, et al.

RNA 2011 17: 1578-1588 originally published online June 21, 2011

Access the most recent version at doi:10.1261/rna.2624511

\section{Supplemental http://rnajournal.cshlp.org/content/suppl/2011/06/13/rna.2624511.DC1 \\ Material}

References This article cites 35 articles, 10 of which can be accessed free at: http://rnajournal.cshlp.org/content/17/8/1578.full.html\#ref-list-1

\section{License}

Email Alerting Receive free email alerts when new articles cite this article - sign up in the box at the Service top right corner of the article or click here. 